Research Article

\title{
Durability Evaluation of Concrete Bridges Based on the Theory of Matter Element Extension-Entropy Weight Method-Unascertained Measure
}

\author{
Qing-fu Li iD and Ying-qiao Yu (D) \\ School of Water Conservancy Engineering Zhengzhou University, Zhengzhou 450001, China \\ Correspondence should be addressed to Ying-qiao Yu; yuyingqiao@gs.zzu.edu.cn
}

Received 2 September 2021; Revised 27 October 2021; Accepted 4 December 2021; Published 27 December 2021

Academic Editor: Denis Benasciutti

Copyright (C) 2021 Qing-fu Li and Ying-qiao Yu. This is an open access article distributed under the Creative Commons Attribution License, which permits unrestricted use, distribution, and reproduction in any medium, provided the original work is properly cited.

\begin{abstract}
To accurately evaluate the durability of reinforced concrete girder bridges, a durability evaluation model was developed based on the matter element extension theory, entropy weight method, and unascertained measure theory. A total of seven indicators were selected for durability evaluation: the concrete presumed strength uniformity coefficient, reinforcement corrosion potential level, chloride ion content, average value of concrete relative carbonation depth, crack width, resistivity, and characteristic value of the reinforcement protective layer thickness. The weights of the durability evaluation indices were assigned using matter element extension combined with the entropy weight method, and the multi-indicator comprehensive evaluation vector was obtained by combining the single-indicator measurement matrix. The evaluation results were analyzed by applying the confidence criterion. The results showed that the evaluation results of this model matched with the actual conditions of the girder bridges, which indicates that this durability evaluation model has good applicability and is reasonable. Finally, a comparative study proved that the model could accurately evaluate the bridge durability.
\end{abstract}

\section{Introduction}

With the development of the social economy and growth of people's aspirations for better lives, China's transportation infrastructure construction, especially bridge engineering construction, has made remarkable achievements. Over the past 40 years, a total of 510,000 new highway bridges have been built, with a combined total length of $48,000 \mathrm{~km}$, equivalent to $80 \%$ of the existing highway bridges. Owing to the material performance characteristics of the bridge, vehicle and crowd loading, and harsh environmental conditions, bridges will inevitably suffer from various diseases, such as reinforcement corrosion, concrete strength decline, cracks, concrete surface damage, and bearing deformation. Such diseases greatly shorten the service lives of bridges and pose a serious threat to people's lives and property safety. Once a bridge is damaged, it will generate high repair costs and construction waste, which will have a negative impact on economic development and ecological protection. Therefore, it is important to ensure the safety and durability of bridge structures.

To evaluate the durability of bridges accurately and objectively, many studies have been conducted by scholars around the world. Anoop [1] used a fuzzy assessment method to predict the service lives of rusted reinforced concrete bridges. Geyskens et al. [2] modified the modulus of elasticity of concrete using a Bayesian approach that effectively took into account the uncertainty of the model and the correlation between the observations. In 1994, Melhem and Aturaliya [3] established a fuzzy comprehensive evaluation method to grade in-service bridges based on structural appearance inspection using fuzzy theory. Liang et al. [4] used AHP (Analytic Hierarchy Process) to determine the relative weights in the durability assessment model. Cai et al. [5] proposed a model for assessing the durability of concrete structures in marine environments. Based on Monte Carlo 
principles, the concrete elements were simulated stochastically using the crystal simulation method. Zheng et al. [6] established a durability evaluation system for concrete bridge structures and introduced time variables. The durability factors at different times were calculated and evaluated, and the evaluation vectors for bridge construction at different times were calculated. Based on the evaluation vectors and the asymmetric method, the durability ratings of concrete bridges at different times were preevaluated. Weyers and Liu [7] developed a service-life prediction model for reinforced concrete structures in a chloride ion erosion environment, which divided the state of chloride ion erosion of reinforced concrete structures in different life stages into the following processes: diffusion to the reinforcement surface, rusting causing cracking, and spalling of concrete. Sasmal [8] combined AHP and fuzzy mathematics to correct the uncertainty of the test data. The durability assessment using reliability theory has a clear physical meaning and is suitable for quantifying the durability of bridges. Zhao et al. [9] used a fuzzy cluster analysis method for the damage diagnosis of concrete bridges, which was based on actual measurement data, avoided human interference, and achieved good results. Long [10] investigated the durability assessment methods of reinforced concrete bridges and demonstrated the feasibility of the matter element extension approach for bridge durability evaluation. Kawamura et al. [11] proposed a state evaluation method based on fuzzy rules and fuzzy neural networks, which could avoid the black-box operations of neural networks, and the fuzzy system became an adaptive fuzzy system with good application prospects.

Unascertained measure theory is an ideal method to handle uncertain information and achieve comprehensive evaluation [12]. In this study, the concrete presumed strength uniformity coefficient, reinforcement corrosion potential level, chloride ion content, average value of the concrete relative carbonation depth, crack width, resistivity, and characteristic value of the reinforcement protective layer thickness were selected as durability evaluation indices of concrete bridges. Using the theory of unascertained measure and combining matter element extension and the entropy weight method, a durability evaluation model of concrete girder bridges was established and two bridges were used as examples for evaluation.

\section{Durability Evaluation Index System Establishment}

According to China's Standards for Technical Condition Evaluation of Highway Bridges [13] (JTH/TH21-2017), the durability level of bridges is divided into five levels, as shown in Table 1.

With a reinforced concrete girder bridge as an example, a total of seven indicators were selected for bridge durability evaluation: concrete presumed strength uniformity coefficient $\left(B_{1}\right)$, reinforcement corrosion potential level $\left(B_{2}\right)$, chloride ion content $\left(B_{3}\right)$, average value of concrete relative carbonation depth $\left(B_{4}\right)$, crack width $\left(B_{5}\right)$, resistivity $\left(B_{6}\right)$, and characteristic value of reinforcement protective layer thickness $\left(B_{7}\right)$. The grading criteria of the evaluation indices are shown in Table 2.

\section{Evaluation Methodology}

\subsection{Unascertained Measure Theory}

3.1.1. Single-Index Measure. Let the domain $A_{1}, A_{2}, \ldots, A_{n}$ consisting of evaluation objects $A=\left\{A_{1}, A_{2}, \ldots, A_{n}\right\}$ be the object space. Any evaluation object $A_{i} \in A(i=1,2, \ldots, n)$ has $m$ evaluation indicators $B_{1}, B_{2}, \ldots, B_{m}$, and $B=\left\{B_{1}, B_{2}, \ldots, B_{m}\right\}$. The measured value of evaluation object $A_{i}$ for evaluation index $B_{j}$ is $x_{i j}(i=1,2, \ldots, n$; $j=1,2, \ldots, m) . x_{i j}$ is divided into $t$ levels $C_{1}, C_{2}, \ldots, C_{t}$, where $C_{k}$ is the $k$ th $(k=1,2, \ldots, t)$ evaluation class and the effect of class $k$ is better than that of class $k+1$, i.e., $C_{k}>C_{k+1}$. We say $C=\left\{C_{1}, C_{2}, \ldots, C_{t}\right\}$ is an ordered partition class of the evaluation space $B$. If $z_{i j k}=z\left(x_{i j} \in C_{k}\right)$, the measurement $x_{i j}$ belongs to the range of the $k$ th rank $C_{k}$ and satisfies the "nonnegative boundedness, normalization, and additivity" properties of the following equations and $z$ is called an unconfirmed measure, or simply a measure [15]:

$$
\begin{aligned}
0 & \leq z\left(x_{i j} \in C_{k}\right) \leq 1, \\
z\left(x_{i j} \in B\right) & =1, \\
z\left(x_{i j} \in \bigcup_{l=1}^{k} C_{l}\right) & =\sum_{l=1}^{k} z\left(x_{i j} \in C_{l}\right) .
\end{aligned}
$$

The matrix $\left(z_{i j k}\right)_{m \times t}$ is a single-index measure matrix of the form

$$
\left(z_{i j k}\right)_{m \times t}=\left[\begin{array}{cccc}
z_{i 11} & z_{i 12} & \cdots & z_{i 1 t} \\
z_{i 21} & z_{i 22} & \cdots & z_{i 2 t} \\
\vdots & \vdots & \vdots & \vdots \\
z_{i m 1} & z_{i m 2} & \cdots & z_{i m t}
\end{array}\right] .
$$

3.1.2. Multi-Index Measure. If $z_{i k}=z\left(A_{i} \in C_{k}\right)$ denotes the degree of affiliation of evaluation object $A_{i}$ to the $k$ th evaluation level, then

$$
z_{i k}=\sum_{j=1}^{m} W_{j} z_{i j k}(i=1,2, \ldots, n ; k=1,2, \ldots, t),
$$

where $z_{i k} \quad$ satisfies $\quad 0 \leq z_{i k} \leq 1 \quad$ and $\quad \sum_{k=1}^{t} z_{i k}=1$. $z_{i}=\left[z_{i 1}, z_{i 2}, \ldots, z_{i t}\right]$ is called a multi-index comprehensive measure evaluation vector of $A_{i}[16]$.

3.2. Distinction Weight of the Single Index. Weights are important parameters in durability evaluations, and the evaluation results of durability mainly depend on the weights. The combined weight assignment method could reflect the evaluation results more accurately. The core concepts of matter element extension theory are promoting the transformation of things and solving incompatible problems, and thus, it is suitable for multi-indicator evaluation [17]. 
TABLE 1: Bridge durability evaluation grade.

\begin{tabular}{|c|c|}
\hline $\begin{array}{l}\text { Durability } \\
\text { grade }\end{array}$ & Condition description \\
\hline I & Good condition, fully functional \\
\hline II & Slightly damaged, with minor defects, no impact on the use of the bridge function \\
\hline III & Medium damaged, with moderate defects, still able to maintain normal use function \\
\hline IV & $\begin{array}{c}\text { Severely damaged, the main components have large defects, significantly affecting the bridge function; cannot guarantee } \\
\text { normal use }\end{array}$ \\
\hline $\mathrm{V}$ & $\begin{array}{c}\text { Extremely dangerous, the main components have severe defects; the main components cannot be used normally, } \\
\text { endangering the safety of the bridge }\end{array}$ \\
\hline
\end{tabular}

TABLE 2: Evaluation criteria for durability of girder bridges.

\begin{tabular}{|c|c|c|c|c|c|}
\hline Evaluation indicators & $\mathrm{I}$ & II & III & IV & $\mathrm{V}$ \\
\hline Concrete presumed strength uniformity, $B_{1}$ & $\geq 0.95$ & 0.9 to 0.95 & 0.8 to 0.9 & 0.7 to 0.8 & $\leq 0.7$ \\
\hline Reinforcement corrosion potential level, $B_{2} / \mathrm{mV}$ & $\geq-200$ & -300 to -200 & -400 to -300 & -500 to -400 & $\leq 500$ \\
\hline Chloride ion content, $B_{3} / \%$ & $<0.15$ & 0.15 to 0.4 & 0.4 to 0.7 & 0.7 to 1.0 & $\geq 1.0$ \\
\hline Average value of concrete relative carbonation depth, $B_{4}$ & 0.5 & $0.5-1.0$ & $1.0-1.5$ & $1.5-2.0$ & $\geq 2.0$ \\
\hline Crack width, $B_{5} / \mathrm{mm}$ & $<0.05$ & 0.05 to 0.1 & 0.1 to 0.15 & 0.15 to 0.2 & $>0.2$ \\
\hline Resistivity, $B_{6} / \Omega . c m$ & $>20,000$ & 15,000 to 20,000 & 10,000 to 15,000 & 5000 to 10,000 & $<5000$ \\
\hline Characteristic value of reinforcement protective layer thickness, $B_{7}$ & $>0.95$ & 0.85 to 0.95 & 0.7 to 0.85 & 0.55 to 0.7 & $\leq 0.55$ \\
\hline
\end{tabular}

Note: the evaluation criteria of the evaluation indices refer to the specifications of the Inspection and Evaluation of Load-Bearing Capacity of Highway Bridges [14].

The standard matter element model uses a simple correlation function or AHP to determine the weights of each evaluation index, which does not objectively reflect the importance differences of each evaluation index in the things to be evaluated. At the same time, a combination of qualitative and quantitative analysis methods and the matter element extension model based on entropy weight, and the correlation function and correlation degree in the extension set are introduced [18]. The theory of the matter element extension-entropy method is able to inherit the advantages of the matter element extension and avoid the influence of subjective human factors.

3.2.1. Theory of Matter Element Extension. Matter element extension theory is an emerging formal model based on the elemental analysis method proposed by Chinese expert Cai Wen and researched by other experts for more than 20 years. The matter element extension model can reduce the subjectivity of the evaluation results and divide the grade of the evaluation objects [19].

The matter element extension evaluation method combines matter element theory and extension sets with a correlation degree for quantitative evaluation. This model divides the data interval of the evaluated target into several orders and determines their levels. The correlation degree is calculated between each plan and the grade. The larger the correlation degree is, the higher the membership extent is. The level of the evaluated target depends on the grade of the data interval with the highest membership degree [20]. A matter element is the basic unit of this method and is a logical structure described by the names, characteristics, and quantities of an object. The basic evaluation processes are described as follows [21]:
(1) Determine the classical domain, section domain, and matrix of elements to be evaluated

Denote the event to be evaluated as $Q$ and the value of the indicator $B$ as $v$. $Q$ has $m$ indicators, denoted as $B_{1}, B_{2}, \ldots, B_{m}$, and the corresponding quantity values are denoted as $v_{1}, v_{2}, \ldots, v_{m}$. The matter element matrix is as follows [22]:

$$
R=\left[\begin{array}{ccc}
Q & B_{1} & v_{1} \\
& B_{2} & v_{2} \\
& \vdots & \vdots \\
& B_{m} & v_{m}
\end{array}\right]=\left[\begin{array}{c}
R_{1} \\
R_{2} \\
\vdots \\
R_{m}
\end{array}\right] .
$$

(a) Determine the classical domain

The classical domain is determined as follows:

$$
\begin{aligned}
R_{k} & =\left(Q_{k}, B_{j}, x_{j k}\right)=\left[\begin{array}{ccc}
Q_{k} & B_{1} & x_{1 k} \\
& B_{2} & x_{2 k} \\
& \vdots & \vdots \\
& B_{m} & x_{m k}
\end{array}\right] \\
& =\left[\begin{array}{ccc}
Q_{k} & B_{1} & a_{1 k}, b_{1 k} \\
& B_{2} & a_{2 k}, b_{2 k} \\
& \vdots & \vdots \\
& B_{m} & a_{m k}, b_{m k}
\end{array}\right],
\end{aligned}
$$

where $R_{k}$ represents the classical domain matter element matrix composed of the characteristic $B$ of the $k$ th evaluation grade $Q_{k}$ and the value range of the characteristic $B, k=1,2, \ldots t . Q_{k}$ is the $k$ th evaluation grade divided; $x_{j k}=$ $\left(a_{m k}, b_{m k}\right)$ is the range of the values of the $j$ th index $B_{j}$ of the $k$ th evaluation grade $Q_{k}$. 
The events to be evaluated are classified into $t$ levels. That is, the range of data taken at each level corresponding to an evaluation index is the classical domain.

(b) Define the section domain

The section domain is defined as follows:

$$
\begin{aligned}
R_{j} & =\left(P, B_{j}, x_{j p}\right)=\left[\begin{array}{ccc}
P & B_{1} & x_{1 p} \\
& B_{2} & x_{2 p} \\
\vdots & \vdots \\
& B_{m} & x_{m p}
\end{array}\right] \\
& =\left[\begin{array}{ccc}
P & B_{1} & a_{1 p}, b_{1 p} \\
B_{2} & a_{2 p}, b_{2 p} \\
\vdots & \vdots \\
B_{m} & a_{m p}, b_{m p}
\end{array}\right],
\end{aligned}
$$

where $P$ is something to be evaluated; $R_{j}$ is a matrix of section domain elements consisting of the characteristic $B_{j}$ of the thing to be evaluated $(P)$, all of its evaluation grades, and the range of values of the characteristic $B_{j} ; x_{j p}=\left(a_{m p}, b_{m p}\right)$ is the range that $P$ measures with respect to $B_{j}$, i.e., the section domain of $P ; a_{m p}$ is the minimum value of the lower limit of the $j$ th index $B_{j}$ in all evaluations; $b_{m p}$ is the maximum value of the upper limit of the $j$ th feature $B$ in all the evaluations; and $x_{j k} \subset x_{j p}$.

(c) Determine the matter element

The matter element $R_{0}$ is determined using the collected statistical data or analysis result:

$$
R_{0}=\left(P_{0}, B_{j}, x_{j}\right)=\left[\begin{array}{ccc}
P_{0} & B_{1} & x_{1} \\
& B_{2} & x_{2} \\
& \vdots & \vdots \\
& B_{m} & x_{m}
\end{array}\right],
$$

where $P_{0}$ indicates a certain definite evaluation system and $x_{j}$ represents $P_{0}$ within the range of values of evaluation index $B_{j}$, which is the specific index data of the object to be evaluated.

(2) Calculate correlation

Determine the correlation function for each level of the system to be evaluated

The correlation function expresses the degree to which something has a certain property, and the concept of distance in the real variable function is extended to a "distance" by the formula of the association function [23]. The correlation function built on the basis of the distance extends the qualitative description of something that has a certain property to a quantitative description of the degree of a certain property [24]. The distance between a point $x$ on the real axis and a certain interval $X_{0}=$ $(a, b)$ is specified as $\rho\left(x, X_{0}\right)=\left|x_{j}-a+b / 2\right|-$ $1 / 2(b-a)$. The primary correlation function for the $j$ th indicator value domain belonging to the $k$ th rank is established as follows:

$$
\begin{aligned}
K_{k}\left(x_{j}\right) & =\left\{\begin{array}{l}
\frac{\rho\left(x_{j}, x_{j k}\right)}{\rho\left(x_{j}, x_{j p}\right)-\rho\left(x_{j}, x_{j k}\right)}, x_{j} x_{j k} \\
\frac{-\rho\left(x_{j}, x_{j k}\right)}{\left|x_{j k}\right|}, x_{j} \in x_{j k}
\end{array},\right. \\
\rho\left(x_{j}, x_{j k}\right) & =\left|x_{j}-\frac{a_{j k}+b_{j k}}{2}\right|-\frac{1}{2}\left(b_{j k}-a_{j k}\right), \\
\rho\left(x_{j}, x_{j p}\right) & =\left|x_{j}-\frac{a_{j p}+b_{j p}}{2}\right|-\frac{1}{2}\left(b_{j p}-a_{j p}\right),
\end{aligned}
$$

where $x_{j}$ is the $j$ th durability evaluation index; $x_{j k}=$ $\left(a_{j k}, b_{j k}\right)$ is the value domain corresponding to the $j$ th indicator with rank $k ; x_{j p}=\left(a_{j p}, b_{j p}\right)$ is the range of values specified for the $j$ th indicator for the whole hierarchy of indicators to be evaluated; and $\left|x_{j k}\right|$ is the length of the interval.

The initial correlation matrix of the object to be evaluated is as follows:

$$
\left(K_{j k}\right)_{m \times t}=\left[\begin{array}{cccc}
K_{11} & K_{12} & \cdots & K_{1 t} \\
K_{21} & K_{22} & \cdots & K_{2 t} \\
\vdots & \vdots & \vdots & \vdots \\
K_{m 1} & K_{m 2} & \cdots & K_{m t}
\end{array}\right],
$$

where $j=1,2, \ldots, m$ and $k=1,2, \ldots, t$.

3.2.2. Entropy Weight Method. The entropy weight method is a commonly used weighting method. The greater the degree of dispersion is, the greater the degree of differentiation is and the more information that can be derived [25]. The entropy method is an objective weighting method. The objective weighting method refers to the method of weighting based on a relevant mathematical method using the attribute value of the indicator itself. The advantage is that the weight can be interpreted and has a theoretical basis [26]. The steps for determining the entropy weight are as follows.

It is assumed that there are $t$ evaluation levels and $m$ evaluation indicators for each object and the data in the correlation matrix $\left(K_{j k}\right)_{m \times t}$ are normalized to the range of $[0,1]$ to create the normalization matrix $\left(r_{j k}\right)_{m \times t}$. The entropy $H_{j}$ of each evaluation index [27] is

$$
H_{j}=-\frac{1}{\ln t} \sum_{k=1}^{t} f_{j k} \ln f_{j k},
$$

where $f_{j k}$ indicates the weight of each indicator. It is calculated as follows:

$$
f_{j k}=\frac{\left(1+r_{j k}\right)}{\sum_{k=1}^{t}\left(1+r_{j k}\right)} .
$$


The weights $W_{j}$ of the evaluation indicators are

$$
W_{j}=\frac{\left(1-H_{j}\right)}{\sum_{j=1}^{m}\left(1-H_{j}\right)},
$$

where $0 \leq W_{j} \leq 1$ and $\sum_{j=1}^{m} W_{j}=1$.

The standardized formula is

$$
r_{j k}=\frac{K_{j k}-\min K_{j k}}{\max K_{j k}-\min K_{j k}},
$$

where $K_{j k}$ is the initial correlation matrix value; $r_{j k}$ is the value of the judgment matrix after the normalization process; and $\min K_{j k}$ and $\max K_{j k}$ are the minimum and maximum values of an evaluation index in the initial correlation matrix, respectively.

\subsubsection{Calculation Steps}

(1) Determine the durability evaluation indices of the system to be evaluated and the grading criterion of each index

(2) Determine the classical domain, section domain, and object element matrix of the system to be evaluated

(3) Calculate the correlation matrix of the system to be evaluated and normalize the correlation matrix

(4) Substitute the judgment matrix obtained from step (3) into equations (12)-(14) to obtain the weight of each durability evaluation index

3.3. Durability Evaluation. A confidence criterion is used to analyze the calculated results, and $\lambda$ is set as the confidence level $(\lambda \geq 0.5)$. $\lambda$ was generally taken as 0.6 or 0.7 . If

$$
k_{0}=\min \left\{k: \sum_{1}^{k} z_{i} \geq \lambda, k=1,2, \ldots, t\right\} \text {, }
$$

then the evaluation object $A_{i}$ is considered to belong to the $k_{0}$ th evaluation level $C_{k_{0}}$.

Based on several theories mentioned above, we drew a flow chart of bridge durability assessment in Figure 1.

\section{Example Application}

Example 1. A reinforced concrete simply supported $\mathrm{T}$-girder bridge has been in use for 15 years with a net width of $11 \mathrm{~m}$ and a span arrangement of $5 \times 20 \mathrm{~m}$. The design load rating of this bridge is highway class I. There is no history of structural maintenance. Cracks exist on the concrete surface with small widths. Linearity is intact, there are no structural abnormal displacements, and corrosion of the reinforcement is present, but to a small extent. The bridge substructure is good. The observed values of the third span $S_{3}$ and the fourth span $S_{4}$ in the original literature [28] were taken for durability evaluation. The observed values of each durability evaluation index for the third span and the fourth span are shown in Table 3.

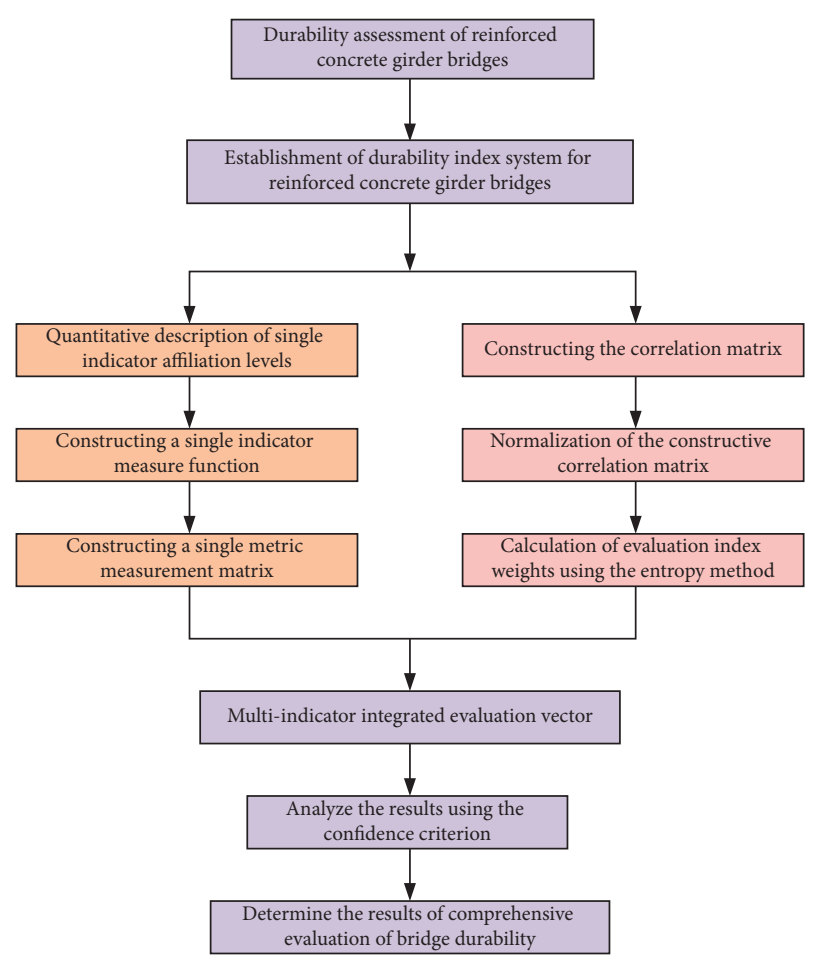

FIGURE 1: Flow chart of bridge durability evaluation.

Example 2. A simply supported plate girder bridge in Gansu Province has a span of $20 \mathrm{~m}$, has been in use for 12 years, has no previous history of structural maintenance, and has a calculated span of $19.50 \mathrm{~m}$. The bridge consists of 14 plate girders with widths of $1.35 \mathrm{~m}$ and heights of $1.00 \mathrm{~m}$. The design load rating is highway class I [29]. The bridge currently has slight holes in the concrete surface, slight corrosion of the reinforcement, linear integrity of the main girders, the presence of a small number of small cracks, no abnormal structural dislocation, a good bridge substructure, and slight wear on the piers. The measured values of each durability evaluation index for the plate girder bridge in Example 2 are shown in Table 4.

\subsection{Calculation of the Weight Value of Each Durability Evaluation Index}

(1) Determine classical domain, section domain, and matrix of elements to be evaluated

(a) Determine the classical domain Since there is an infinite interval for durability evaluation index grading, the classical domain and section domain of the object element cannot be determined. According to the literature [10], an upper (lower) limit can be taken in an infinite interval to constitute a finite interval and the selected upper (lower) limit does not affect the calculation result of the index correlation. Therefore, the classical domain matrix is as follows: 
TABLe 3: Measured values of durability evaluation indices of a simply supported T-girder bridge.

\begin{tabular}{lccccccc}
\hline \multirow{2}{*}{ Location } & \multicolumn{9}{c}{ Durability evaluation indices } \\
& $B_{1}$ & $B_{2}(\mathrm{mV})$ & $B_{3}(\%)$ & $B_{4}$ & $B_{5}(\mathrm{~mm})$ & $B_{6}(\Omega . \mathrm{cm})$ & 18,652 \\
\hline$S_{3}$ & 0.91 & -180 & 0.13 & 0.61 & 0.12 & 0.92 \\
$S_{4}$ & 0.87 & -264 & 0.20 & 0.60 & 0.16 & 14,783 \\
\hline
\end{tabular}

TABle 4: Measured values of the durability evaluation index of simply supported plate girder bridge.

\begin{tabular}{cccccccc}
\hline \multirow{2}{*}{ Location } & \multicolumn{8}{c}{ Durability evaluation indices } \\
& $B_{1}$ & $B_{2}(\mathrm{mV})$ & $B_{3}(\%)$ & $B_{4}$ & $B_{5}(\mathrm{~mm})$ & $B_{6}(\Omega . \mathrm{cm})$ & $B_{7}$ \\
\hline $\mathrm{Q}$ & 0.93 & -32 & 0.15 & 0.75 & 0.13 & 18,000 \\
\hline
\end{tabular}

$$
\left[\begin{array}{ccccc}
(0.95,1) & (0.9,0.95) & (0.8,0.9) & (0.7,0.8) & (0.6,0.7) \\
(-200,0) & (-300,-200) & (-400,-300) & (-500,-400) & (-600,-500) \\
(0,0.15) & (0.15,0.4) & (0.4,0.7) & (0.7,1.0) & (1.0,1.2) \\
(0,0.5) & (0.5,1.0) & (1.0,1.5) & (1.5,2.0) & (2.0,3.0) \\
(0,0.05) & (0.05,0.1) & (0.1,0.15) & (0.15,0.2) & (0.2,0.3) \\
(20000,30000) & (15000,20000) & (10000,15000) & (5000,10000) & (4000,5000) \\
(0.95,1.0) & (0.85,0.95) & (0.7,0.85) & (0.55,0.7) & (0.5,0.55)
\end{array}\right],
$$

where the horizontal row of the matrix indicates the durability evaluation level and the vertical row indicates the durability evaluation index.

(b) The section domain is as follows:

$$
R=\left[\begin{array}{ccc}
P & B_{1} & (0.6,1) \\
& B_{2} & (-600,0) \\
B_{3} & (0,1.2) \\
B_{4} & (0,3) \\
B_{5} & (0,0.3) \\
B_{6} & (4000,30000) \\
B_{7} & (0.5,1.0)
\end{array}\right] .
$$

(c) Determine the matter element The matter element is as follows:

$$
R_{3}=R=\left[\begin{array}{ccc}
P_{3} & B_{1} & 0.91 \\
& B_{2} & -180 \\
B_{3} & 0.13 \\
B_{4} & 0.61 \\
B_{5} & 0.12 \\
B_{6} & 18652 \\
B_{7} & 0.92
\end{array}\right],
$$

$$
R_{3}=R=\left[\begin{array}{ccc}
P_{4} & B_{1} & 0.87 \\
B_{2} & -264 \\
B_{3} & 0.20 \\
B_{4} & 0.60 \\
B_{5} & 0.16 \\
B_{6} & 14783 \\
B_{7} & 0.90
\end{array}\right],
$$

(2) Calculate correlations

The third span $S_{3}$ and indicator $B_{1}$ were selected as an example. The correlations were as follows: 


$$
\begin{aligned}
& K_{1}\left(x_{1}\right)=\frac{0.04}{-0.09-0.04}=-0.31 \\
& K_{1}\left(x_{2}\right)=-\frac{-0.01}{0.05}=0.2 \\
& K_{1}\left(x_{3}\right)=\frac{0.01}{-0.09-0.01}=-0.1, \\
& K_{1}\left(x_{4}\right)=\frac{0.11}{-0.09-0.11}=-0.55 \\
& K_{1}\left(x_{5}\right)=\frac{0.21}{-0.09-0.21}=-0.7 .
\end{aligned}
$$

Similarly, the correlations of several other indicators were obtained, and the correlation matrices of the durability evaluation indicators were as follows:

$$
\text { third span } S_{3}:\left[\begin{array}{ccccc}
-0.31 & 0.2 & -0.1 & -0.55 & -0.7 \\
0.1 & -0.1 & -0.4 & -0.55 & -0.64 \\
0.13 & -0.13 & -0.68 & -0.81 & -0.87 \\
-0.15 & 0.22 & -0.39 & -0.59 & -0.70 \\
-0.37 & -0.14 & 0.4 & -0.2 & -0.4 \\
-0.11 & 0.27 & -0.24 & -0.43 & -0.55 \\
-0.27 & 0.3 & -0.47 & -0.73 & -0.82
\end{array}\right] \text {, }
$$

(3) Calculate weights

After standardizing the correlation degree matrix of the durability evaluation indices obtained in the previous step, the following judgment matrices were obtained:

$$
\text { third span } S_{3}:\left[\begin{array}{ccccc}
0.44 & 1 & 0.67 & 0.17 & 0 \\
1 & 0.73 & 0.32 & 0.12 & 0 \\
1 & 0.73 & 0.19 & 0.06 & 0 \\
0.59 & 1 & 0.33 & 0.11 & 0 \\
0.04 & 0.32 & 1 & 0.25 & 0 \\
0.54 & 1 & 0.37 & 0.14 & 0 \\
0.49 & 1 & 0.32 & 0.08 & 0
\end{array}\right] \text {, }
$$

The obtained judgment matrices were introduced into the entropy weight method in equations (11)-(13), and the following weights of each durability evaluation index were obtained:

$$
\begin{aligned}
W_{3} & =[0.1369,0.1406,0.1469,0,1415,0.1499,0.1401,0.1441], \\
W_{4} & =[0.1459,0.1430,0.1473,0.1454,0.1297,0.1391,0.1496], \\
W_{Q} & =[0.1369,0.1581,0.1397,0.1399,0.1400,0.1331,0.1523] .
\end{aligned}
$$

\subsection{Determination of the Single-Index Unascertained Measure} Function and Matrix. Reasonable construction of singleindicator unascertained measure functions is the key to applying unascertained measure theory for durability evaluation. It is assumed that the attribute of the evaluation object is $e_{l}$ at the initial stage and the attribute is in state $l$. In the process of changing the attribute value from $e_{l}$ to $e_{l+1}$, the state of the evaluation object also changes, with state $l$ tending to weaken and state $l+1$ tending to strengthen. When the evaluation object's attribute value changes to $e_{l+1}$, state $l$ of the evaluation object's attribute disappears completely to 0 and state $l+1$ of the attribute increases to 1 . The form of the unascertained measure reflects the change in the state of the evaluation object's attributes, and the evaluator 
should construct the corresponding unascertained measure function according to the severity of the state change of the evaluation object [30]. There are four common distributions of unascertained measure functions, linear, parabolic, sinusoidal, and exponential, with linear generally being more widely used. Table 5 shows the expressions and graphs of the linear unascertained measure functions. The unascertained measure functions for each durability evaluation metric are shown in Figure 2.

The actual observed values of each durability evaluation index in Tables 3 and 4 were introduced into the corresponding single-index measure functions to obtain singleindex unascertained measure matrices:

$$
\begin{aligned}
\left(z_{3 j k}\right)_{7 \times 5} & =\left[\begin{array}{ccccc}
0 & 0.8 & 0.2 & 0 & 0 \\
1 & 0 & 0 & 0 & 0 \\
1 & 0 & 0 & 0 & 0 \\
0.56 & 0.44 & 0 & 0 & 0 \\
0 & 0.1 & 0.9 & 0 & 0 \\
0.46 & 0.54 & 0 & 0 & 0 \\
0.4 & 0.6 & 0 & 0 & 0
\end{array}\right], \\
\left(z_{4 j k}\right)_{7 \times 5} & =\left[\begin{array}{ccccc}
0 & 0.733 & 0.267 & 0 & 0 \\
0 & 0.86 & 0.14 & 0 & 0 \\
0.6 & 0.4 & 0 & 0 & 0 \\
0.6 & 0.4 & 0 & 0 & 0 \\
0 & 0 & 0.3 & 0.7 & 0 \\
0 & 0.457 & 0.543 & 0 & 0 \\
0 & 1 & 0 & 0 & 0
\end{array}\right], \\
\left(z_{Q j k}\right)_{7 \times 5} & =\left[\begin{array}{ccccc}
0.2 & 0.8 & 0 & 0 & 0 \\
1 & 0 & 0 & 0 & 0 \\
1 & 0 & 0 & 0 & 0 \\
0 & 1 & 0 & 0 & 0 \\
0 & 0 & 0.9 & 0.1 & 0 \\
0.2 & 0.8 & 0 & 0 & 0 \\
1 & 0 & 0 & 0 & 0
\end{array}\right] .
\end{aligned}
$$

4.3. Determination of the Multi-Index Comprehensive Measure Evaluation Vector. Based on the single-index unascertained measure matrix and the durability evaluation index weight vector obtained in the previous two sections, the multi-index comprehensive measure evaluation vectors calculated by equation (3) were as follows:

$$
\begin{aligned}
z_{3 k} & =[0.489,0.349,0.162,0,0], \\
z_{4 k} & =[0.176,0.560,0.173,0.090,0], \\
z_{Q k} & =[0.504,0.356,0.126,0.014,0] .
\end{aligned}
$$

With the confidence level $\lambda=0.7$, according to equation (15), the following is obtained for the third span:
$S_{3}: 0.489+0.349=0.838>0.7$. Therefore, the durability evaluation grade of the third span of this reinforced concrete girder bridge was II. For the fourth span, $S_{4}: 0.176+0.560=0.736>0.7$. Therefore, the durability evaluation grade of the fourth span of this reinforced concrete girder bridge was II. For simply supported plate girder bridges: $0.504+0.356=0.860>0.7$. The durability evaluation grade of the simply supported plate girder bridge was II. The evaluation results are consistent with those in the literature $[28,29]$, and they are in line with the actual engineering situation. This indicated that the reinforced concrete simply supported T-girder bridge and the plate girder bridge were in good condition, with minor damage, and they need to be properly inspected and maintained on a daily basis.

\section{Comparative Study}

5.1. Standardization of Evaluation Indicators. The indicators in Table 2 were normalized and made dimensionless using the polar difference method [31]. The standardized equation of the evaluation index that is positively correlated with the durability evaluation level is $X_{j k}=x_{j k}-\min$ $x_{j k} / \max x_{j k}-\min x_{j k}$, and the standardized equation of the evaluation index that is negatively correlated with the durability evaluation level is $X_{j k}=x_{j k}-\max x_{j k} / \max x_{j k}-$ $\min x_{j k}$, where $x_{j k}$ is the value of the evaluation index and $\min x_{j k}$ and $\max x_{j k}$ are the minimum and maximum values of the evaluation index, respectively. The standardized values are shown in Table 6.

5.2. Simple Correlation Function Method. The weight values of each indicator were calculated by the simple correlation function method, and the calculation process [32] was as follows:

$$
s_{j k}=\left\{\begin{array}{l}
\frac{2\left(x_{j}-a_{j k}\right)}{b_{j k}-a_{j k}}, x_{j} \leq \frac{a_{j k}+b_{j k}}{2} \\
\frac{2\left(b_{j k}-x_{j}\right)}{b_{j k}-a_{j k}}, x_{j} \geq \frac{a_{j k}+b_{j k}}{2}
\end{array},\right.
$$

where $s_{j k}$ denotes the correlation of the $j$ th indicator with the $k$ th evaluation level; $x_{j}$ denotes the sample value of the $j$ th indicator; $j=1,2, \ldots, m$; and $k=1,2, \ldots, t$.

$$
\begin{aligned}
& \text { If } x_{j} \in x_{j p} \text {, then } \\
& \qquad s_{j k_{\max }}\left(x_{j}, x_{j k_{\max }}\right)=\max _{k}\left\{s_{j k}\left(x_{j}, x_{j k}\right)\right\} .
\end{aligned}
$$

The greater the level into which the data of indicator $B_{j}$ falls, the greater the weight that should be assigned to that indicator. Thus,

$$
s_{j}=\left\{\begin{array}{l}
k_{\max } \times\left(1+s_{j k_{\max }}\left(x_{j}, x_{j k}\right)\right), s_{j k_{\max }}\left(x_{j}, x_{j k}\right) \geq-0.5 \\
k_{\max } \times 0.5, s_{j k_{\max }}\left(x_{j}, x_{j k}\right) \leq-0.5
\end{array},\right.
$$


TABLE 5: Function graphs and expressions.

\begin{tabular}{ll}
\hline Distribution form \\
Linear distribution
\end{tabular}$\left\{\begin{array}{l}\text { Function expressions } \\
z_{l}(x)=\left\{\begin{array}{l}-x / e_{l+1}-e_{l}+e_{l+1} / e_{l+1}-e_{l}, e_{l}<x \leq e_{l+1} \\
0, x>e_{l+1} \\
0, x \leq e_{l+1} \\
x / e_{l+1}-e_{l}-e_{l} / e_{l+1}-e_{l}, e_{l}<x \leq e_{l+1}\end{array}\right. \\
z_{l+1}(x)=x\end{array}\right.$

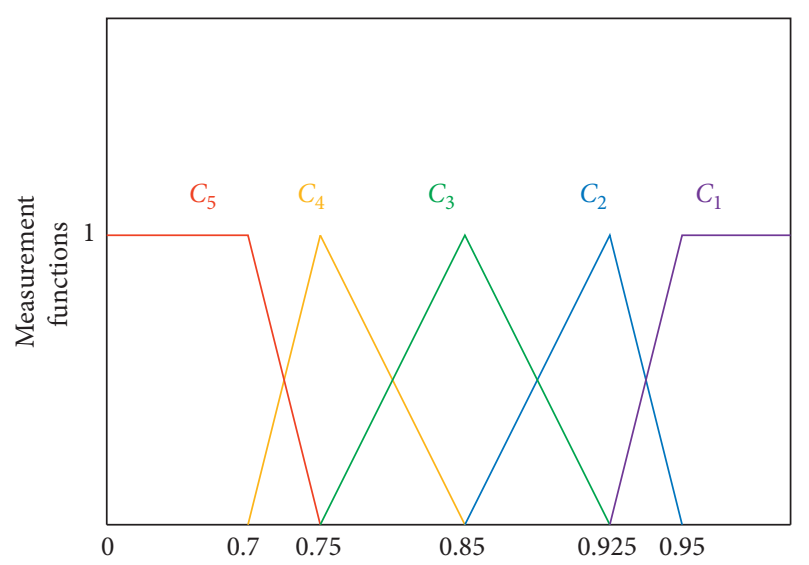

(a)

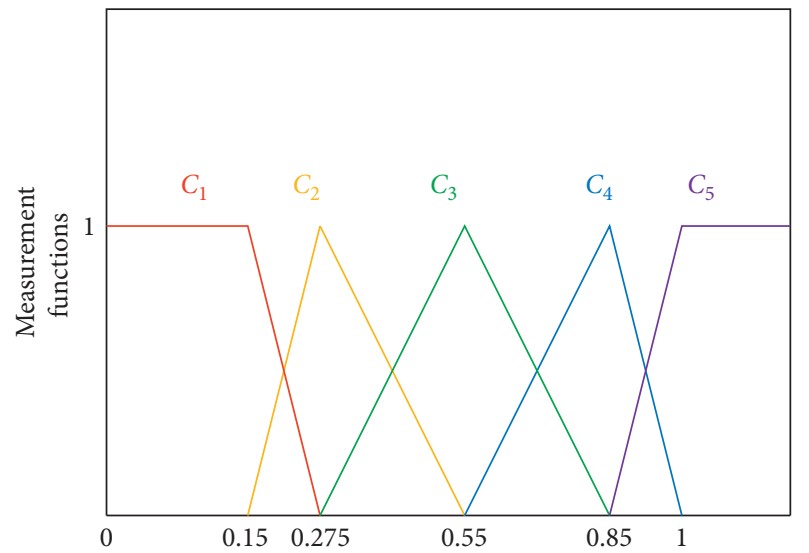

(c)

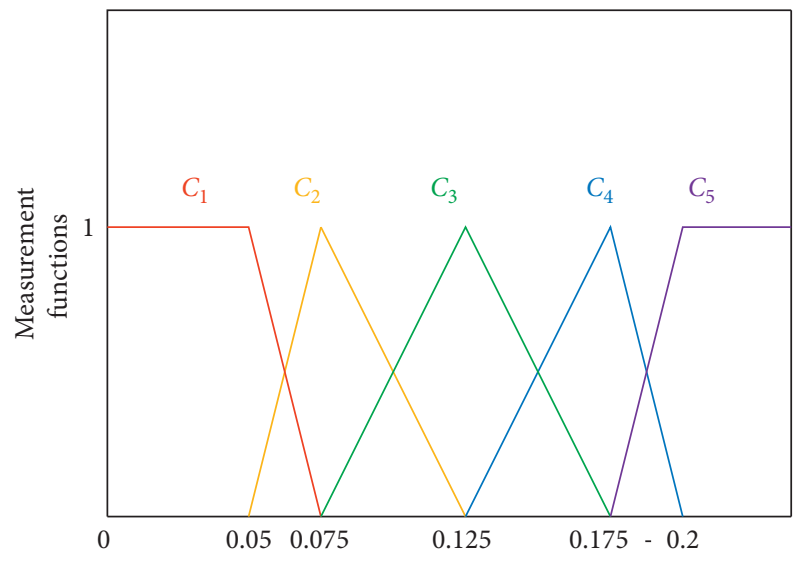

(e)

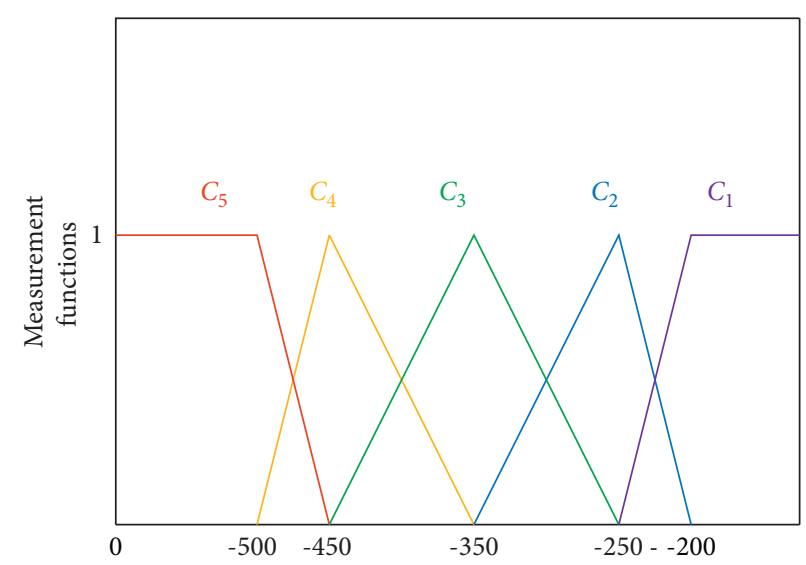

(b)

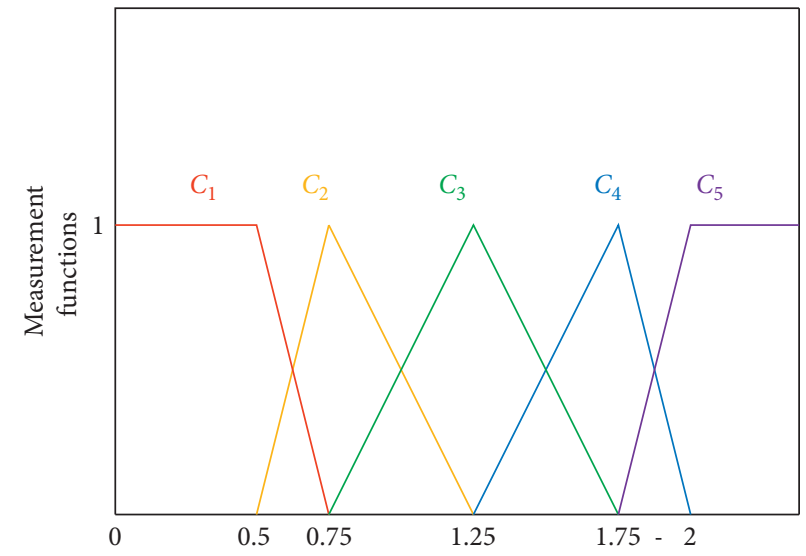

(d)

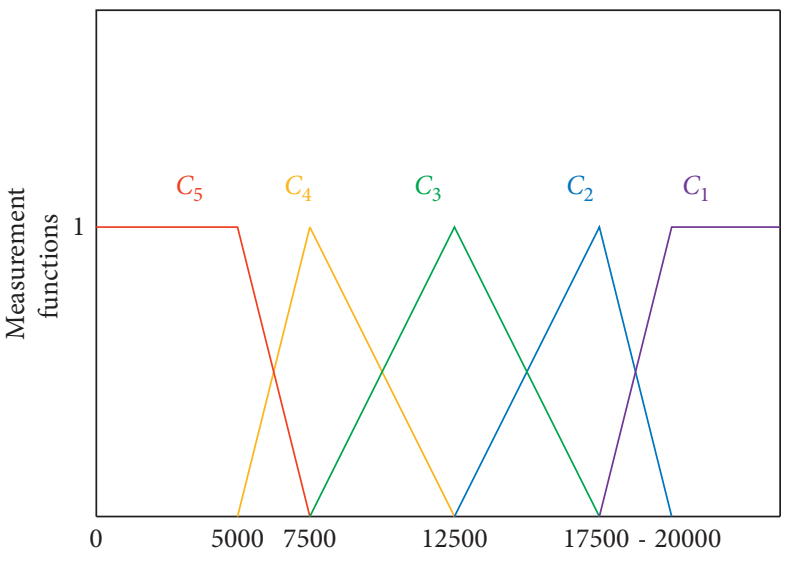

(f)

Figure 2: Continued. 


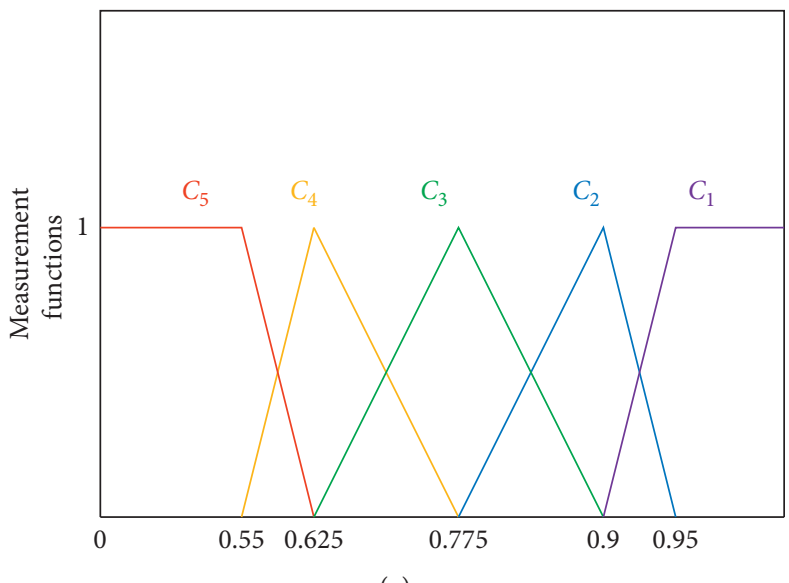

(g)

Figure 2: Measurement function of each durability evaluation index. (a) Concrete strength index measurement function. (b) Rabar corrosion index measurement function. (c) Chloride ion content index measurement function. (d) Concrete carbonation index measurement function. (e) Crack index measurement function. (f) Resistivity index measurement function. (g) Protective layer index measurement function for steel reinforcement.

TABLE 6: Standard data of the durability index.

\begin{tabular}{|c|c|c|c|c|c|}
\hline Evaluation indicators & $\mathrm{I}$ & II & III & IV & $\mathrm{V}$ \\
\hline Concrete presumed strength uniformity coefficient, $B_{1}$ & $(0,0.125]$ & $(0.125,0.25)$ & $(0.25,0.5)$ & $(0.5,0.75)$ & {$[0.75,1)$} \\
\hline Reinforcement corrosion potential level, $B_{2}$ & $(0,0.33]$ & $(0.33,0.5)$ & $(0.5,0.67)$ & $(0.67,0.83)$ & {$[0.83,1)$} \\
\hline Chloride ion content, $B_{3}$ & $(0,0.125)$ & $(0.125,0.33)$ & $(0.33,0.58)$ & $(0.58,0.83)$ & $(0.83,1)$ \\
\hline Average value of concrete relative carbonation depth, $B_{4}$ & $(0,0.17)$ & $(0.17,0.33)$ & $(0.33,0.5)$ & $(0.5,0.67)$ & $(0.67,1)$ \\
\hline Crack width, $B_{5}$ & $(0,0.17)$ & $(0.17,0.33)$ & $(0.33,0.5)$ & $(0.5,0.67)$ & $(0.67,1)$ \\
\hline Resistivity, $B_{6}$ & $(0,0.38)$ & $(0.38,0.58)$ & $(0.58,0.77)$ & $(0.77,0.96)$ & $(0.96,1)$ \\
\hline Characteristic value of reinforcement protective layer thickness, $B_{7}$ & $(0,0.1)$ & $(0.1,0.3)$ & $(0.3,0.6)$ & $(0.6,0.9)$ & $(0.9,1)$ \\
\hline
\end{tabular}

where $k_{\max }$ represents the evaluation grade into which the sample value of index $j$ in the element to be evaluated falls. The larger the value is, the more restrictive the index is to treat the matter.

Conversely, if the data for indicator $B_{j}$ fall into a larger level, a smaller weight should be assigned to that indicator. Thus,

$s_{j}=\left\{\begin{array}{l}\left(t-k_{\max }+1\right) \times\left(1+s_{j k_{\max }}\left(x_{j}, x_{j k}\right)\right), s_{j k_{\max }}\left(x_{i}, x_{j k}\right) \geq-0.5 \\ \left(t-k_{\max }+1\right) \times 0.5, s_{j k_{\max }}\left(x_{j}, x_{j k}\right) \leq-0.5\end{array}\right.$,

where $t$ is the number of categories assigned to each indicator.

The weight of indicator $B_{j}$ is as follows:

$$
W_{j}=\frac{s_{j}}{\sum_{j=1}^{m} s_{j}} \text {. }
$$

5.3. Durability Evaluation. The correlation of the durability evaluation level $k$ of the system to be evaluated is as follows:

$$
s_{k}\left(P_{0}\right)=\sum_{j=1}^{m} W_{j} s_{j k}
$$

If $s_{k 0}\left(P_{0}\right)=\max _{k \in\{1,2, \ldots, t\}} s_{k}\left(P_{0}\right)$, then the assessment $P_{0}$ belongs to grade $C_{k_{0}}$.
5.4. Example Analysis. The durability evaluation indices were normalized to obtain the classical and section domains, as follows:

$$
\begin{aligned}
& {\left[\begin{array}{ccccc}
(0,0.125) & (0.125,0.25) & (0.25,0.5) & (0.5,0.75) & (0.75,1) \\
(0,0.33) & (0.33,0.5) & (0.5,0.67) & (0.67,0.83) & (0.83,1) \\
(0,0.125) & (0.125,0.33) & (0.33,0.58) & (0.58,0.83) & (0.83,1) \\
(0,0.17) & (0.17,0.33) & (0.33,0.5) & (0.5,0.67) & (0.67,1) \\
(0,0.17) & (0.17,0.33) & (0.33,0.5) & (0.5,0.67) & (0.67,1) \\
(0,0.38) & (0.38,0.58) & (0.58,0.77) & (0.77,0.96) & (0.96,1) \\
(0,0.1) & (0.1,0.3) & (0.3,0.6) & (0.6,0.9) & (0.9,1)
\end{array}\right],} \\
& R=\left[\begin{array}{ccc}
P & B_{1} & (0,1) \\
& B_{2} & (0,1) \\
B_{3} & (0,1) \\
B_{4} & (0,1) \\
B_{5} & (0,1) \\
B_{6} & (0,1) \\
B_{7} & (0,1)
\end{array}\right] .
\end{aligned}
$$

The measured values of each durability evaluation index were normalized to obtain the following matter element matrices: 


$$
\begin{aligned}
& R_{3}=\left[\begin{array}{ccc}
P_{3} & B_{1} & 0.255 \\
& B_{2} & 0.03 \\
B_{3} & 0.11 \\
B_{4} & 0.20 \\
B_{5} & 0.4 \\
B_{6} & 0.44 \\
B_{7} & 0.156
\end{array}\right], \\
& R_{4}=\left[\begin{array}{ccc}
P_{3} & B_{1} & 0.325 \\
& B_{2} & 0.44 \\
& B_{3} & 0.17 \\
B_{4} & 0.20 \\
B_{5} & 0.53 \\
B_{6} & 0.59 \\
& B_{7} & 0.20
\end{array}\right] \\
& R_{Q}=\left[\begin{array}{ccc}
P_{3} & B_{1} & 0.175 \\
& B_{2} & 0.05 \\
& B_{3} & 0.125 \\
B_{4} & 0.25 \\
B_{5} & 0.43 \\
B_{6} & 0.46 \\
& B_{7} & 0.04
\end{array}\right]
\end{aligned}
$$

The correlation degree of each durability evaluation index was calculated according to equations (4)-(10), and the specific calculation process was not repeated. The results are shown in Tables 7-9.

According to equations (16)-(30), the weights of each durability evaluation index were calculated by the simple correlation function method and the results are shown in Tables 10-12.

According to equation (31), the correlations of grade $k$ were calculated as follows:

$$
\begin{aligned}
s_{k}(3) & =[-0.22,0.11,-0.14,-0.50,-0.63], \\
s_{k}(4) & =[-0.30,0.11,-0.08,-0.43,-0.58], \\
s_{k}(Q) & =[-0.14,-0.03,-0.29,-0.52,-0.64] .
\end{aligned}
$$

Therefore, the durability evaluation grade of the third and fourth spans of the reinforced concrete simply supported T-girder bridge and the plate girder bridge was II.

By comparison, it was determined that the final evaluation results of the two bridge durability evaluation methods were consistent. However, the use of the matter element extension-entropy weight method-unascertained measure theory for durability evaluation can reduce the
TABLE 7: Third cross-durability evaluation index correlation.

\begin{tabular}{cccccc}
\hline & $s_{j 1}$ & $s_{j 2}$ & $s_{j 3}$ & $s_{j 4}$ & $s_{j 5}$ \\
\hline$B_{1}$ & -0.31 & 0.2 & -0.1 & -0.55 & -0.7 \\
$B_{2}$ & 0.1 & -0.1 & -0.4 & -0.55 & -0.64 \\
$B_{3}$ & 0.13 & -0.13 & -0.675 & -0.81 & -0.87 \\
$B_{4}$ & -0.15 & -0.22 & -0.39 & -0.59 & -0.695 \\
$B_{5}$ & -0.37 & -0.14 & 0.4 & -0.2 & -0.4 \\
$B_{6}$ & -0.11 & 0.27 & -0.24 & -0.43 & -0.55 \\
$B_{7}$ & -0.27 & 0.3 & -0.47 & -0.73 & -0.82 \\
\hline
\end{tabular}

TABLE 8: Fourth cross-durability evaluation index correlation.

\begin{tabular}{cccccc}
\hline & $s_{j 1}$ & $s_{j 2}$ & $s_{j 3}$ & $s_{j 4}$ & $s_{j 5}$ \\
\hline$B_{1}$ & -0.38 & -0.19 & 0.3 & -0.35 & -0.56 \\
$B_{2}$ & -0.20 & 0.16 & 0.36 & -0.34 & -0.47 \\
$B_{3}$ & -0.2 & 0.2 & -0.5 & -0.71 & -0.8 \\
$B_{4}$ & -0.14 & 0.2 & -0.4 & -0.6 & -0.7 \\
$B_{5}$ & -0.44 & -0.3 & -0.07 & 0.2 & -0.22 \\
$B_{6}$ & -0.33 & -0.02 & 0.04 & -0.31 & -0.48 \\
$B_{7}$ & -0.33 & 0.5 & -0.33 & -0.67 & -0.78 \\
\hline
\end{tabular}

TABLE 9: Correlation of durability evaluation index for the plate girder bridge.

\begin{tabular}{cccccc}
\hline & $s_{j 1}$ & $s_{j 2}$ & $s_{j 3}$ & $s_{j 4}$ & $s_{j 5}$ \\
\hline$B_{1}$ & -0.22 & 0.4 & -0.3 & -0.65 & -0.77 \\
$B_{2}$ & 0.16 & -0.84 & -0.89 & -0.92 & -0.94 \\
$B_{3}$ & 0 & 0 & -0.625 & -0.79 & -0.85 \\
$B_{4}$ & -0.25 & 0.5 & -0.25 & -0.5 & -0.625 \\
$B_{5}$ & -0.38 & -0.19 & 0.18 & -0.13 & -0.35 \\
$B_{6}$ & -0.14 & 0.2 & -0.2 & -0.4 & -0.52 \\
$B_{7}$ & 0.4 & -0.6 & -0.87 & -0.93 & -0.96 \\
\hline
\end{tabular}

Table 10: Third cross-evaluation index weight values.

\begin{tabular}{lccccccc}
\hline Indicators & $B_{1}$ & $B_{2}$ & $B_{3}$ & $B_{4}$ & $B_{5}$ & $B_{6}$ & $B_{7}$ \\
\hline Weights & 0.23 & 0.05 & 0.06 & 0.13 & 0.24 & 0.14 & 0.14 \\
\hline
\end{tabular}

TABLE 11: Fourth cross-evaluation index weight values.

\begin{tabular}{lccccccc}
\hline Indicators & $B_{1}$ & $B_{2}$ & $B_{3}$ & $B_{4}$ & $B_{5}$ & $B_{6}$ & $B_{7}$ \\
\hline Weights & 0.09 & 0.08 & 0.12 & 0.06 & 0.05 & 0.41 & 0.20 \\
\hline
\end{tabular}

TABLE 12: Evaluation index weight value of the plate girder bridge.

\begin{tabular}{lccccccc}
\hline Indicators & $B_{1}$ & $B_{2}$ & $B_{3}$ & $B_{4}$ & $B_{5}$ & $B_{6}$ & $B_{7}$ \\
\hline Weights & 0.14 & 0.11 & 0.08 & 0.16 & 0.27 & 0.14 & 0.09 \\
\hline
\end{tabular}

influence of human subjective factors in the evaluation process, with significant theoretical advantages, a relatively easy calculation process, and more accurate calculation results.

\section{Conclusions}

(1) Based on the various factors that affect the durability of reinforced concrete girder bridges, seven indicators-concrete presumed strength uniformity coefficient, reinforcement corrosion potential level, 
chloride ion content, average value of concrete relative carbonation depth, crack width, resistivity, and characteristic value of reinforcement protective layer thickness-were selected to establish the durability evaluation system and the rating criteria for each indicator were graded.

(2) The influence factors of reinforced concrete girder bridges were uncertain, the combination of the matter element extension and entropy weight method was applied to assign weights to each durability evaluation index, which effectively avoided the influence of human subjective factors in the fuzzy comprehensive evaluation method, and the evaluation results were more accurate and reasonable.

(3) A complete durability evaluation model for reinforced concrete girder bridges was established based on matter element extension-entropy weight method-unascertained measure theory. Two reinforced concrete girder bridges were taken as examples for durability evaluation, and the evaluation results basically matched with the actual condition of the bridge. Thus, the applicability of the model was illustrated.

(4) Through a comparative study with a simple correlation function method, matter element extension, it was found that the final evaluation results of the two methods were consistent, which proved that the model could evaluate the bridge durability more accurately. Because of the advantages of the three methods (matter element extension, entropy method, and unascertained measure), the calculation process was simple and the results were more accurate.

\section{Data Availability}

The data used to support the findings of this study are included within the article.

\section{Conflicts of Interest}

The authors declare that there are no conflicts of interest regarding the publication of this paper.

\section{References}

[1] M. B. Anoop, K. B. Rao, and T. V. S. R. A. Rao, "Application of fuzzy sets for estimating service life of reinforced concrete structural members in corrosive environments," Engineering Structures, vol. 24, no. 9, pp. 1229-1242, 2002.

[2] P. Geyskens, A. D. Kiureghian, and P. Monteiro, "Bayesian prediction of elastic modulus of concrete," Journal of Structural Engineering, vol. 124, no. 1, pp. 89-95, 1998.

[3] H. G. Melhem and S. Aturaliya, "Bridge condition rating using an eigenvector of priority settings," Computer-Aided Civil and Infrastructure Engineering, vol. 11, no. 6, pp. 421-432, 1996.

[4] M.-T. Liang, J.-H. Wu, and C.-H. Liang, "Multiple layer fuzzy evaluation for existing reinforced concrete bridges," Journal of Infrastructure Systems, vol. 7, no. 4, pp. 144-159, 2001.
[5] J. G. Cai, F. H. Dong, and Z. L. Luo, "Durability of concrete bridge structure under marine environment," Journal of Coastal Research, vol. 83, pp. 429-435, 2018.

[6] X. Z. Zheng and J. F. Lin, "Pre-evaluation of durability for concrete bridge," Advanced Materials Research, vol. 2091, pp. 1581-1585, 2012.

[7] Y. P. Liu and R. E. Weyers, "Modeling the time-to-corrosion cracking in chloride contaminated reinforced concrete structures," ACI Materials Journal, vol. 95, no. 6, pp. 675-681, 1998.

[8] S. Sasmal and K. Ramanjaneyulu, "Condition evaluation of existing reinforced concrete bridges using fuzzy based analytic hierarchy approach," Expert Systems with Applications, vol. 35, no. 3, pp. 1430-1443, 2008.

[9] Z. Zhao and C. Chen, "Concrete bridge deterioration diagnosis using fuzzy inference system," Advances in Engineering Software, vol. 32, no. 4, pp. 317-325, 2001.

[10] T. Z. Long, Research on Durability Assessment Methods of the Reinforced Concrete Bridges, School of Civil Transportaion Engineering Guangdong University of Technology, China, 2013.

[11] K. Kawamura, A. Miyamoto, D. M. Frangopol, and R. Kimura, "Performance evaluation of concrete slabs of existing bridges using neural networks," Engineering Structures, vol. 25, no. 12, pp. 1455-1477, 2003.

[12] Y. Z. Chang, Y. Yang, and S. C. Dong, "Comprehensive sustainability evaluation of high-speed railway (HSR) construction projects based on unascertained measure and analytic hierarchy process," Sustainability, vol. 10, no. 2, 2018.

[13] JTG/T H21-2011, China's Standards for Technical Condition Evaluation of Highway Bridges, National Standards of the People's Republic of China, Beijing, China, 2011.

[14] JTG/T J21-2011, Specification for Inspection and Evaluation of Load-Bearing Capacity of Highway Bridges, National Standards of the People's Republic of China, Beijing, China, 2011.

[15] S. L. Wu, X. D. Du, and S. Yang, "Rock mass quality evaluation based on unascertained measure and intuitionistic fuzzy sets," Complexity, vol. 2020, Article ID 5614581, 14 pages, 2020.

[16] K. Zhao, Q. Wang, and Y. J. Yan, "Geological structural surface evaluation model based on unascertained measure," Geofluids, vol. 2019, Article ID 3547384, 7 pages, 2019.

[17] X. Wu, S. Liu, Y. Sun, Y. An, S. Dong, and G. Liu, "Ecological security evaluation based on entropy matter-element model: a case study of Kunming city, southwest China," Ecological Indicators, vol. 102, pp. 469-478, 2019.

[18] Y. Song, H. W. Yang, N. Xu, and X. Guo, "Power system risk research based on entropy weight matter element extension model," IOP Conference Series: Earth and Environmental Science, vol. 242, no. 2, 2019.

[19] Q. Yan, H. Dong, and M. Zhang, "Service evaluation of electric vehicle charging station: an application of improved matter-element extension method," Sustainability, vol. 13, no. 14, p. 7910, 2021.

[20] G. Liang, D. Niu, and Y. Liang, "Core competitiveness evaluation of clean energy incubators based on matterelement extension combined with TOPSIS and KPCA-NSGAII-LSSVM," Sustainability, vol. 12, no. 22, p. 9570, 2020.

[21] B. Aorui, Z. S. Luo, Y. L. Kong, and L. Zhao, "Comprehensive weighted matter-element extension method for the safety evaluation of underground gas storage," Royal Society Open Science, vol. 7, no. 4, Article ID 191302, 2020.

[22] X. C. Luo, Z. L. Wang, Y. Guan, and L. Lu, "Supply chain flexibility evaluation based on matter-element extension," Complexity, vol. 2020, Article ID 8057924, 12 pages, 2020. 
[23] W. Cai, "Extension theory and its applications," Chinese Science Bulletin, Springer, New York, NY, USA, 1999.

[24] W. Cai, "Overview of Extension Theory," Systems EngineeringTheory and Practice, Springer, New York, NY, USA, 1998.

[25] Y. X. Zhu, D. Z. Tian, and F. Yan, "Effectiveness of entropy weight method in decision-making," Mathematical Problems in Engineering, vol. 2020, Article ID 3564835, 5 pages, 2020.

[26] Q. Y. Li, G. M. Chen, and B. Pietro, "Effectiveness evaluation of missile electromagnetic launch system based on ADC model improved by EWM-FAHP-ICWGT," Mathematical Problems in Engineering, vol. 2020, Article ID 7208563, 19 pages, 2020.

[27] Y. Li, J. Yang, H. Shi, and Y Li, “Assessment of sustainable urban transport development based on entropy and unascertained measure," PLoS One, vol. 12, no. 10, Article ID e0186893, 2017.

[28] P. Zheng, Research on Durability Evaluation and Prediction of Concrete Beam Bridge Based on Extension Theory, Chang'an University, Zian, China, 2019.

[29] N. J. Chai and X. Y. Bao, "Based on improved similarityunascertained measure theory durability assessment of highway bridges," Journal of Railway Science and Engineering, vol. 15 , no. 10, pp. 2541-2548, 2018.

[30] C. F. Huang, S. G. Tian, Q. Li, and J. Huang, "Evaluation of rock quality of tunnel wall rock based on rough set theory and unascertained measurement theory," Mathematical Problems in Engineering, vol. 2018, Article ID 3571028, 10 pages, 2018.

[31] X. Cao, C. Wei, and D. Xie, "Evaluation of scale management suitability based on the entropy-TOPSIS method," Land, vol. 10, no. 4, p. 416, 2021.

[32] Q. Li, H. D. Zhou, H. Zhou, and H. Zhang, "Durability evaluation of highway tunnel lining structure based on matter element extension-simple correlation function method-cloud model: a case study," Mathematical Biosciences and Engineering, vol. 18, no. 4, pp. 4027-4054, 2021. 